\title{
PERENCANAAN PONDASI TIANG PANCANG PADA GEDUNG UNIVERSITAS TULUNGAGUNG
}

\author{
Imam Mustofa ${ }^{1 *}$, Sigit Winarto ${ }^{2}$, Ahmad Ridwan $^{3}$ \\ Fakultas Teknik Universitas Kadiri \\ Email : ${ }^{*}$ Imam.must21@gmail.com,${ }^{2}$ sigit.winarto@unik-kediri.ac.id, ${ }^{3}$ ahmad- \\ ridwan@unik-kediri.a.id
}

\begin{abstract}
The foundation is an important part of the structure of the building. In particular, multi-storey buildings are now increasingly used, both private homes and public facilities. The foundation is the load bearing element of the column which then channels it to the hard soil layer. Piles are construction parts that are made of wood, concrete, steel or steel, which are used to carry surface loads to lower surface levels in the soil. The purpose of this final project is to be able to calculate / find out the load on the building, the dimensions and depth of the pile foundation, the need for reinforcement and the stability of the control to match the load borne.
\end{abstract}

Keywords: Foundation, Reinforced Concrete, Pile, Loading

\begin{abstract}
Abstrak
Pondasi merupakan salah satu bagian penting dalam struktur bangunan. Khususnya bangunan gedung bertingkat yang sekarang ini semakin banyak digunakan, baik rumah pribadi maupun fasilitas umum. Pondasi adalah elemen pemikul beban dari kolom yang kemudian menyalurkannya ke lapisan tanah keras. Tiang pancang adalah bagian - bagian konstruksi yang di buat dari kayu, beton, dana tau baja, yang digunakan untuk meneruskan beban - beban permukaan ke tingkat - tingkat permukaan yang lebih rendah di dalam masa tanah. Tujuan dari tugas akhir ini agar dapat menghitung/ mengetahui pembebanan pada bangunan, dimensi serta kedalaman pondasi tiang pancang, kebutuhan tulangan dan stabilitas kontrol agar sesuai dengan beban yang dipikul.
\end{abstract}

Kata Kunci: Pondasi, Beton Bertulang, Tiang Pancang, Pembebanan 


\section{PENDAHULUAN}

Kebutuhan Bentuk struktur tanah merupakan suatu peranan yang penting dalam suatu pekerjaan konstruksi yang harus dicermati karena kondisi ketidak tentuan dari tanah yang berbeda beda. Sebelum melaksanakan suatu pembangunan konstruksi yang pertama tama di lakukan dan dikerjakan di lapangan adalah pekerjaan pondasi (struktur bawah) [1]. Pondasi merupakan suatu pekerjaan yang sangat penting dalam suatu pekerjaan Teknik sipil, karena pondasi inilah yang memiliki dan menahan suatu beban yang bekerja di atasnya yaitu beban konstruksi atas. Pondasi ini akan menyalurkan tegangan - tegangan yang terjadi pada beban struktur atas ke dalam lapisan tanah yang keras yang dapat memikul beban konstruksi tersebut. Tiang pancang berintegrasi dengan tanah untuk menghasilkan daya dukung yang mampu memikul dan memberikan keamanan pada struktur atas [2]. Untuk menghasilkan daya dukung yang akurat maka diperlukan suatu penyelidikan tanah yang akurat juga [3][4]. Ada dua metode yang bisa digunakan dalam penentuan kapasitas daya dukung tiang pancang yaitu dengan menggunakan metode statis dan dinamis [5].

\subsection{Umum}

\section{METODE PENELITIAN}

Pondasi adalah elemen pemikul beban dari kolom yang kemudian menyalurkannya ke lapisan tanah keras. Pondasi beton bertulang dapat berupa pondasi pelat setempat atau pondasi lajur [6]. Pada bangunan yang berada pada lapisan tanah dengan daya dukung jelek, terkadang digunakan pula sistem pondasi rakit (raft foundation) beton bertulang [7]. Tiang pancang adalah bagian - bagian konstruksi yang di buat dari kayu, beton, dana tau baja, yang digunakan untuk meneruskan beban - beban permukaan ke tingkat - tingkat permukaanyang lebih rendah di dalam masa tanah. Pondasi adalah elemen pemikul beban dari kolom yang kemudian menyalurkannya ke lapisan tanah keras [8][9]. Pondasi beton bertulang dapat berupa pondasi pelat setempat atau pondasi lajur. Pada bangunan yang berada pada lapisan tanah dengan daya dukung jelek, terkadang digunakan pula sistem pondasi rakit (raft foundation) beton bertulang [10][11][12]. Tiang pancang adalah bagian - bagian konstruksi yang di buat dari kayu, beton, dana tau baja, yang digunakan untuk meneruskan beban - beban permukaan ke tingkat - tingkat permukaanyang lebih rendah di dalam masa tanah [13][14].

\subsection{Pembebanan}

Beban adalah gaya luar yang bekerja pada suatu struktur[15][16]. Penentuan secara pasti besarnya beban yang bekerja pada suatu struktur selama umur layaknya merupakan salah satu pekerjaan yang cukup sulit. Besar beban yang bekerja pada suatu struktur diatur oleh peraturan 
pembebanan yang berlaku. Beberapa jenis beban yang sering dijumpai antara lain[6]:

a. Beban Mati

Beban mati adalah beban gravitasi yang berasal dari berat semua komponen gedung/bangunan yang bersifat permanen selama masa layan struktur tersebut [17].

Tabel 1. Besarnya Beban Mati

\begin{tabular}{|c|c|}
\hline Beban Mati & Besar Beban \\
\hline Baja & $7850 \mathrm{~kg} / \mathrm{m} 3$ \\
\hline Beton bertulang & $2400 \mathrm{~kg} / \mathrm{m} 3$ \\
\hline Dinding 1/2 bata & $250 \mathrm{~kg} / \mathrm{m} 2$ \\
\hline Dinding 1 bata & $450 \mathrm{~kg} / \mathrm{m} 2$ \\
\hline Pas. Batu kali & $2.00-2.20 \mathrm{ton} / \mathrm{m} 3$ \\
\hline Beban tanah & $1.60-2.00 \mathrm{ton} / \mathrm{m} 3$ \\
\hline Atap, usuk, reng & $50 \mathrm{~kg} / \mathrm{m} 2$ \\
\hline
\end{tabular}

b. Beban Hidup

Beban hidup termasuk kedalam beban gravitasi, yaitu jenis beban yang timbul akibat penggunaan suatu gedung selama masa layan gedung tersebut [18][19]. Oleh karena besar dan lokasi beban hidup berubah-ubah, maka penentuan beban hidup dengan tepat merupakan suatu hal yang cukup sulit [20][21]. 
Tabel 2. Besarnya Beban Hidup

\begin{tabular}{|c|c|}
\hline Beban Hidup & Besar Beban \\
\hline $\begin{array}{c}\text { Lantai, tangga, } \\
\text { rumah tinggal } \\
\begin{array}{c}\text { Lantai, tangga, } \\
\text { rumah sederhana, dan gudang }\end{array}\end{array}$ & $200 \mathrm{~kg} / \mathrm{m} 2$ \\
\hline $\begin{array}{c}\text { Lantai sekolah, ruang } \\
\text { kuliah, kantor, toko }\end{array}$ & $125 \mathrm{~kg} / \mathrm{m} 2$ \\
\hline $\begin{array}{c}\text { Lantai ruang } \\
\text { olahraga }\end{array}$ & $250 \mathrm{~kg} / \mathrm{m} 2$ \\
\hline Lantai ruang dansa & $400 \mathrm{~kg} / \mathrm{m} 2$ \\
\hline $\begin{array}{c}\text { Lantai dan balkon } \\
\text { ruang pertemuan lain }\end{array}$ & $500 \mathrm{~kg} / \mathrm{m} 2$ \\
\hline
\end{tabular}

c. Beban Gempa

Beban Gempa adalah semua beban statik ekivalen yang bekerja pada gedung yang menirukan pengaruh dari gerakan tanah akibat gempa tersebut [22]. Beban gempa di dapat dari hasil perhitungan gaya geser dasar nominal V yang diperoleh dari rumus: Beban Gempa adalah semua beban statik ekivalen yang bekerja pada gedung yang menirukan pengaruh dari gerakan tanah akibat gempa tersebut[23]. Beban gempa di dapat dari hasil perhitungan gaya geser dasar nominal $\mathrm{V}$ yang diperoleh dari rumus:

$\mathrm{V}=\mathrm{C} \times \mathrm{I} \times \mathrm{W} / \mathrm{R}$

d. Beban Angin

Beban Angin adalah semua beban yang bekerja pada gedung atau bagian gedung yang disebabkan oleh selisih dalam tekanan udara $(\mathrm{kg} / \mathrm{m} 2)$

dengan:

$$
p=\frac{V^{2}}{16}\left(\mathrm{~kg} / \mathrm{m}^{2}\right)
$$

\subsection{Data Perencanaan}

Dalam pelaksanaan dan penyusunan laporan tugas akhir penulis melakukan pengamatan di lokasi Gedung Universitas Tulungagung, di Jl. Kimangunsarkoro, Desa Beji, Kecamatan Boyolangu, Kabupaten Tulungagung dengan data-data yang akan direncanakan. 


\subsection{Pengumpulan Data}

Untuk meninjau kembali perhitungan perencanaan pondasi tiang pancang pada Gedung Universitas Tulungagung, di Jl. Kimangunsarkoro, Desa Beji, Kecamatan Boyolangu, Kabupaten Tulungagung ini, penulis memperoleh data dari instansi terkait antara lain data beban struktur, hasil sondir, hasil SPT, hasil kelendering dan gambar struktur.

\subsection{Data Teknis Tiang Pancang}

Dari Sondir yang dilakukan di gedung Universitas Tulungagung ini, kita bisa mengetahui rencana dan ukuran pondasi tiang pancang yang akan digunakan. Untuk rencana gedung yang mau dibangun di Universitas Tulungagung ini berukuran $20 \mathrm{~m}$ x 22m, berjumlah 4 lantai.

\section{HASIL DAN PEMBAHASAN}

\subsection{Pembebanan}

Beban Mati Lantai 4

Beban Hidup Lantai 4

Beban Mati Lantai 3

Beban Hidup Lantai 3

Beban Mati Lantai 2

Beban Hidup Lantai 2

Beban Mati Lantai 1

Beban Hidup Lantai 1

*Beban Total

*Beban Gempa

$$
\mathrm{Tx}=\mathrm{Ty}
$$

$\mathrm{H}$

$\mathrm{Tx}=\mathrm{Ty}$

*Beban Angin

$$
\begin{aligned}
& =521758,8 \mathrm{Kg} \\
& =110000 \mathrm{Kg} \\
& =591838,8 \mathrm{Kg} \\
& =110000 \mathrm{Kg} \\
& =626398,8 \mathrm{Kg} \\
& =110000 \mathrm{Kg} \\
& =626398,8 \mathrm{Kg} \\
& =110000 \mathrm{Kg} \\
& = \\
& =2806395,4 \mathrm{Kg} \\
& =2806,4 \mathrm{Ton}
\end{aligned}
$$

$$
\begin{aligned}
& =0,06 \mathrm{H}^{3 / 4} \\
& =28,77 \mathrm{~m} \\
& =0,06(28,77) 3 / 4 \\
& =0,7 \text { detik }
\end{aligned}
$$

$$
\begin{aligned}
& p=\frac{V^{2}}{16}\left(\mathrm{~kg} / \mathrm{m}^{2}\right) \\
& \mathrm{p}=39,063 \mathrm{~kg} / \mathrm{m}^{2}
\end{aligned}
$$




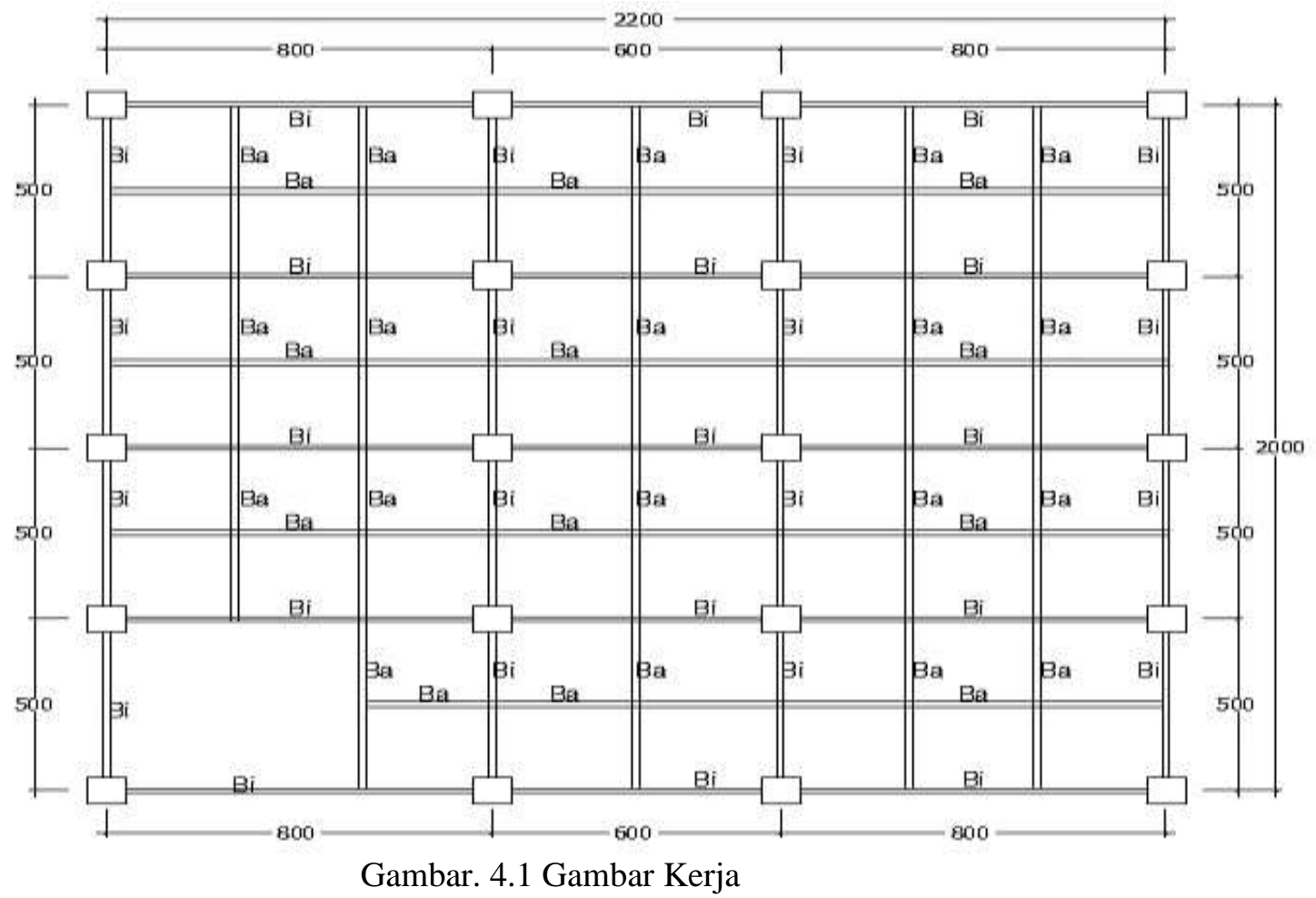

\subsection{Dimensi Pondasi}

Ukuran pondasi tiang pancang yang didapat dari perhitungan :

$$
\begin{array}{ll}
\text { Panjang } & =1.90 \mathrm{~m} \\
\text { Lebar } & =0.80 \mathrm{~m} \\
\text { Tinggi } & =0.60 \mathrm{~m} \\
\text { Kedalanman } & =1.35 \mathrm{~m} \text { dari muka tanah }
\end{array}
$$




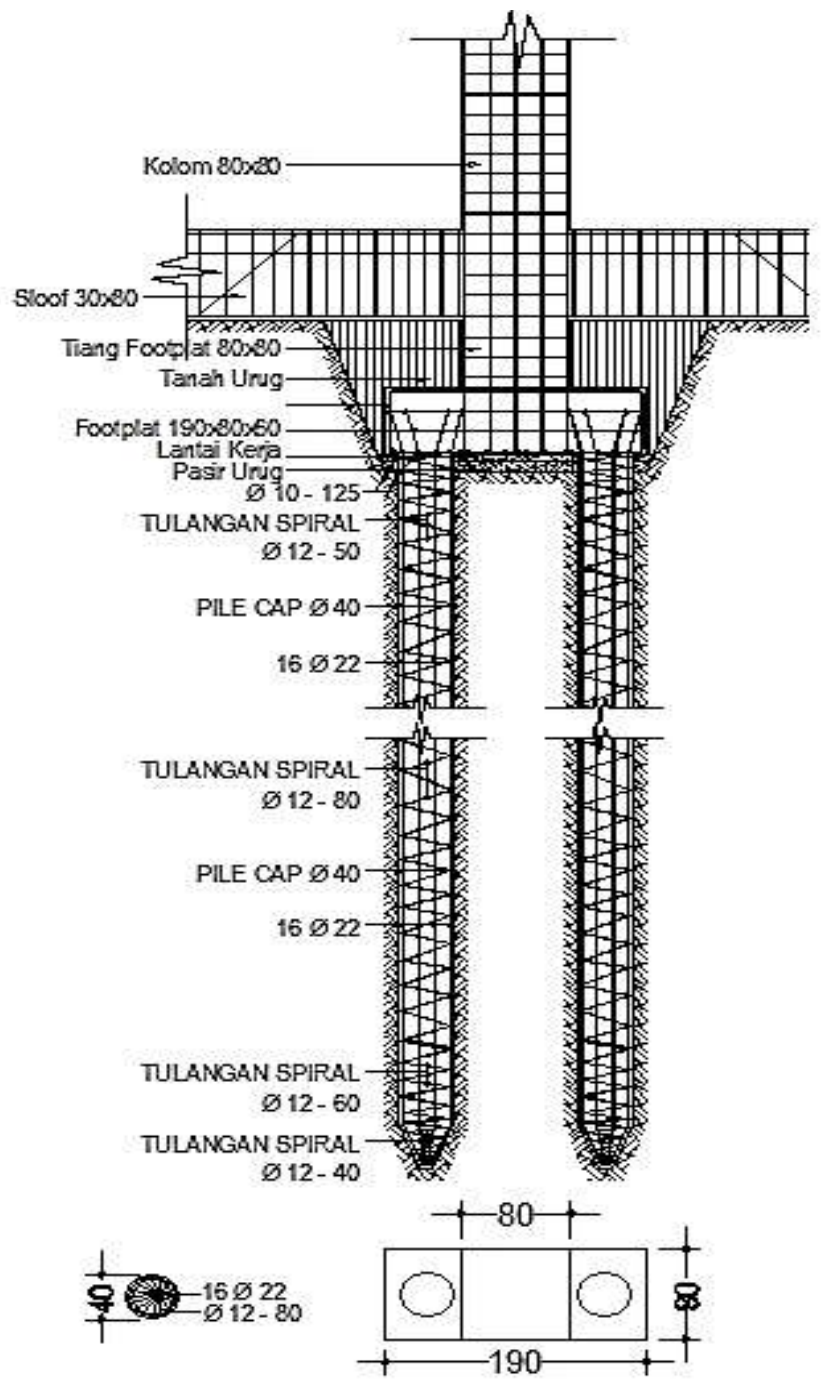

Gambar. 4.2 Gambar Pondasi Tiang Pancang

\subsection{Kebutuhan Tulangan dan Stabilitas Kontrol Pondasi}

*Menghitung tulangan yang dibutuhkan Diameter tulangan utama

$\mathrm{D}=22 \mathrm{~mm}$

A Stulangan $=1 / 4 \times \pi \mathrm{Xd}^{2}$

$=379,94 \mathrm{~mm}^{2}$

Jumlah tulangan yang dibutuhkan, As / Astulangan $=15,471$

$=16$ buah

Digunakan tulangan, 16 - D 22 Maka tulangan yang dibutuhkan :

(Koefisien x panjang x jumlah) Tiap pondasi membutuhkan

$=2.985 \times 15.75 \times 16 \times 2$

Total tulangan pondasi

$=1.504,44 \times 20$

*Stabilitas Kontrol 


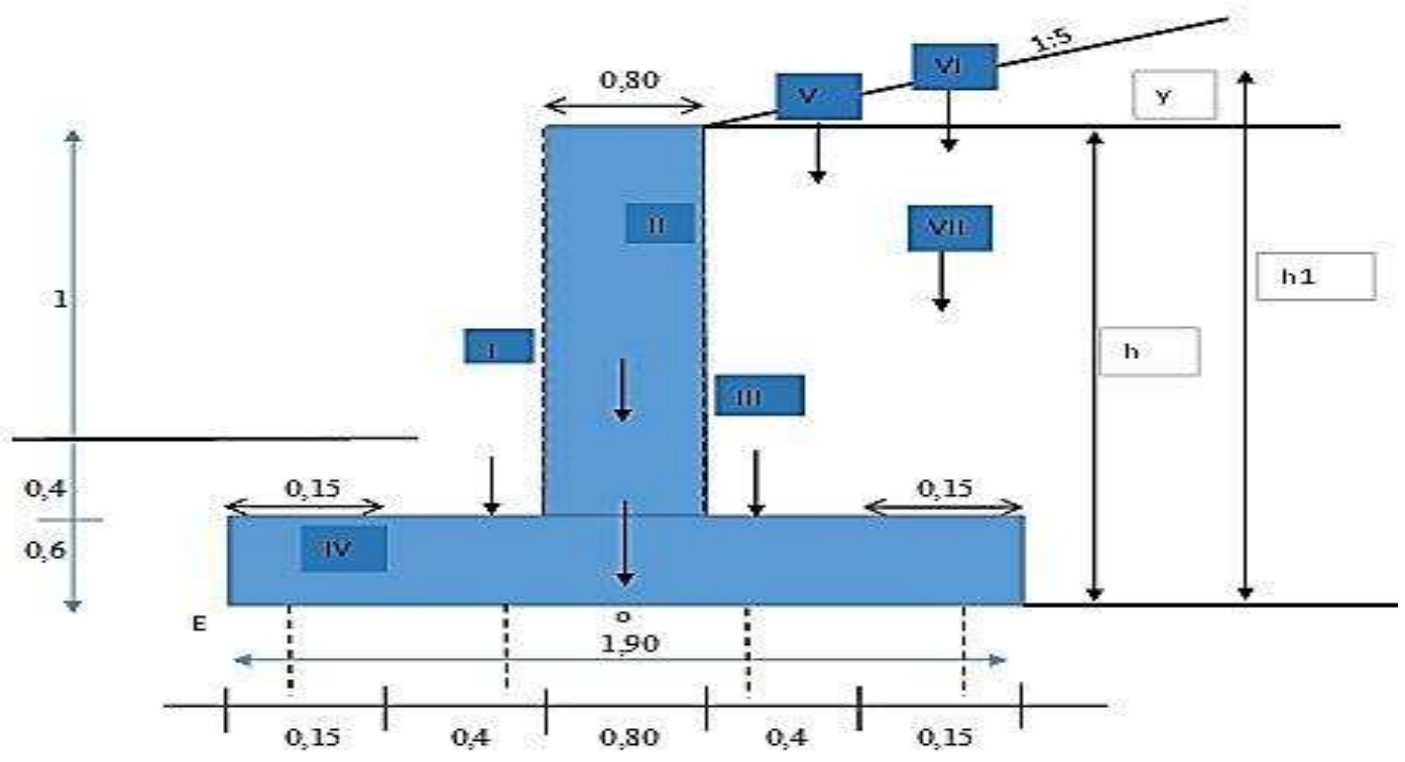

Cek Guling

$\mathrm{n}=\mathrm{MP} / \mathrm{MG} 9,176 \mathrm{t} / \mathrm{m} 2 \gg>1,5 \mathrm{t} / \mathrm{m} 2$

maka AMAN

Cek Geser

$\mathrm{n}=\Sigma \mathrm{W} / \Sigma \mathrm{E} 6,221 \mathrm{t} / \mathrm{m} 2 \gg>1,5 \mathrm{t} / \mathrm{m} 2$

maka AMAN

Penurunan Kekuatan Tumit

Terhadap Geser

$0,0953 \mathrm{t} / \mathrm{m} 2 ~ \gg>15 \mathrm{t} / \mathrm{m} 2$

maka AMAN

Terhadap Tarik

$0,0508 \mathrm{t} / \mathrm{m} 2 ~ \gg>30 \mathrm{t} / \mathrm{m} 2$

maka AMAN

Penurunan Kekuatan Kaki

Terhadap Geser

$0,8279 \mathrm{t} / \mathrm{m} 2 ~ \gg>15 \mathrm{t} / \mathrm{m} 2$

maka AMAN

Terhadap Tarik

$0,4156 \mathrm{t} / \mathrm{m} 2 ~ \gg>30 \mathrm{t} / \mathrm{m} 2$

maka AMAN

Penurunan Kekuatan Badan

б.max $2,7480 \mathrm{t} / \mathrm{m} 2 \gg>150 \mathrm{t} / \mathrm{m} 2$

maka AMAN

$\sigma . \min 2,9209 \mathrm{t} / \mathrm{m} 2>>300 \mathrm{t} / \mathrm{m} 2$

maka AMAN

\section{KESIMPULAN DAN SARAN}

\subsection{Kesimpulan}

Berdasarkan perencanaan pondasi tiang pancang didapat beberapa kesimpulan, yakni sebagai berikut:

1. Hasil pembebanan pada bangunan lantai 1 sampai 4 dengan Peraturan 
Pembebanan Indonesia untuk Gedung 1983, didapat :

2. Dimensi pondasi rencana yang digunakan sesuai perhitungan adalah panjang 1.90 $\mathrm{m} \times$ lebar $0.80 \mathrm{~m}$ x tinggi $0.60 \mathrm{~m}$, dengan kedalaman $1.35 \mathrm{~m}$ dari muka tanah.

3. *Tulangan Pondasi Tiang Pancang yang dipakai menggunakan besi diameter $22 \mathrm{~mm}$, jarak 200mm, jumlah besi per pile cap 16 buah, dengan total tulangan yang diperlukan $30.088,80 \mathrm{~kg}$.

*Stabilitas kontrol pondasi

Cek Guling

$\mathrm{n}=\mathrm{MP} / \mathrm{MG} 9,176 \mathrm{t} / \mathrm{m} 2 \gg>1,5 \mathrm{t} / \mathrm{m} 2$ maka AMAN

Cek Geser

$\mathrm{n}=\Sigma \mathrm{W} / \Sigma \mathrm{E} 6,221 \mathrm{t} / \mathrm{m} 2>>1,5 \mathrm{t} / \mathrm{m} 2 \quad$ maka AMAN

Penurunan Kekuatan Tumit

Terhadap Geser

$0,0953 \mathrm{t} / \mathrm{m} 2$ > $15 \mathrm{t} / \mathrm{m} 2$

maka AMAN

Terhadap Tarik

$0,0508 \mathrm{t} / \mathrm{m} 2$ >> $30 \mathrm{t} / \mathrm{m} 2$

maka AMAN

Penurunan Kekuatan Kaki

Terhadap Geser

$0,8279 \mathrm{t} / \mathrm{m} 2$ >> $15 \mathrm{t} / \mathrm{m} 2$

maka AMAN

Terhadap Tarik

$0,4156 \mathrm{t} / \mathrm{m} 2$ >> $30 \mathrm{t} / \mathrm{m} 2$

maka AMAN

Penurunan Kekuatan Badan

$\sigma \cdot \max 2,7480 \mathrm{t} / \mathrm{m} 2>>>150 \mathrm{t} / \mathrm{m} 2$

maka AMAN

$\sigma \cdot \min 2,9209 \mathrm{t} / \mathrm{m} 2 \gg>>300 \mathrm{t} / \mathrm{m} 2$

maka AMAN

\subsection{Saran}

1. Perencanaan pondasi tidak hanya berpedoman pada ilmu tetapi dipertimbangkan pula pada pedoman yang biasa dilaksanakan di lapangan.

2. Untuk mendapat hasil yang akurat, maka dibutuhkan pemahaman yang menyeluruh tentang tahap - tahap dalam proses perencanaan, dan teori - teori yang didapat di bangku kuliah harus selalu dikembangkan.

\section{UCAPAN TERIMAKASIH}

Dalam penyusunan artikel ini, penulis ucapkan terimakasih kepada dosen pembimbing dan Universitas Kadiri. Penulis berharap agar artikel ini dapat bermanfaat bagi pembaca. 


\section{DAFTAR PUSTAKA}

[1] F. Haliq, "Islam Madura: Studi Konflik, Adaptasi, Harmoni Kelas Menengah Madura Setelah Keruntuhan Orde Baru," 2010.

[2] H. C. Hardiyatmo, “Analisa dan Perancangan Fondasi bagian 1.” Gadjah Mada University Press, Jogjakarta, 2010.

[3] P. Anugrah and H. Erny, "Desain Pondasi Tahan Gempa Sesuai SNI 03-1726-2002 dan SNI 03-2847-2002,” Andi, Yogyakarta, 2013.

[4] A. I. Candra, A. Yusuf, and A. R. F, "Studi Analisis Daya Dukung Pondasi Tiang Pada Pembangunan Gedung Lp3m Universitas Kadiri,” CIVILLa, vol. 3, no. 2, pp. 166-171, 2018.

[5] E. Bowles Joseph, “Analisa dan Desain Pondasi jilid 1," Penerbit Erlangga, Jakarta, 1986.

[6] A. I. Candra, "Analisis Daya Dukung Pondasi Strauss Pile pada Pembangunan Gedung Mini Hospital Universitas Kadiri," Ukarst, vol. 1, no. 1, pp. 63-70, 2017.

[7] A. Andayana, "ANALISIS PERBANDINGAN DAYA DUKUNG TIANG PANCANG BERDASARKAN UJI SPT DAN DAYA DUKUNG TIANG PANCANG BERDASARKAN ALAT HSPD 120T,” 2016.

[8] J. Tambunan, "Studi Analisis Daya Dukung Pondasi Tiang Pancang," J. Ranc. Sipil, vol. 1, no. 1, pp. 21-30, 2012.

[9] C.-K. Wang, C. G. Salmon, and B. Hariandja, "Desain Beton Bertulang Jilid 1," Jakarta: Erlangga, 1990.

[10] I. D. Husodo, Manajemen Proyek Dan Konstruksi Jilid 1. Jakarta, 1995.

[11] W. Hadi Pratomo, "Struktur Beton Prategang (Teori dan Prinsip Desain)," Nova, 1994.

[12] A. I. Manu, "Dasar-Dasar Perencanaan Jembatan Beton Bertulang," PT Mediat. Saptakarya, DPU, 1995.

[13] P. P. D. A. N. P. T. PERMUKIMAN and P. Wilayah, "STANDAR PERENCANAAN KETAHANAN GEMPA UNTUK STRUKTUR BANGUNAN GEDUNG SNI-17262002.” Pusat Penelitian dan Pengembangan Teknologi Permukiman, Bandung, 2002.

[14] H. Frick, Mekanika Teknik 2, Statika dan Kegunaannya. Kanisius, 1979.

[15] F. Febriantoro, Y. C. S. Purnomo, and A. Ridwan, "Study Perencanaan Pondasi Tiang Pancang Jembatan Sembayat Baru II Kecamatan Manyar Kabupaten Gresik,” J. Manaj. Teknol. Tek. Sipil, vol. 1, no. 1, pp. 148-159, 2018, doi: 10.30737/jurmateks.v1i1.147.

[16] T. Y. Purnomo, L. D. Krisnawati, and Y. C. S. Purnomo, "Kajian Jembatan Kecamatan Sendang (Ruas Jalan Tugu-Pabyongan) Kabupaten Tulungagung dengan Metode 
Komposit," J. Manaj. Teknol. Tek. Sipil, vol. 1, no. 1, pp. 112-125, 2018, doi: 10.30737/jurmateks.v1i1.145.

[17] A. Aminudin and N. Z. Devi, "ANALISIS DAYA DUKUNG PONDASI BORED PILE PADA PROYEK PEMBANGUNAN JALAN TOL BAWEN-SALATIGA PAKET 3.1.” Fakultas Teknik UNISSULA, 2016.

[18] A. Pamungkas and E. Harianti, "Desain Pondasi Tahan Gempa Sesuai SNI03-1726-2002 dan SNI 03-2847-2002," 2002.

[19] B. S. Nasional, "Tata cara perencanaan ketahanan gempa untuk struktur bangunan gedung dan non gedung," Sni, vol. 1726, p. 2012, 2012.

[20] S. - 1726- 2002, "STANDAR PERENCANAAN KETAHANAN GEMPA UNTUK STRUKTUR BANGUNAN GEDUNG,” vol. 7798393, no. April, 2002.

[21] D. P. Umum, "Peraturan Pembebanan Indonesia untuk Gedung," Bandung: Stensil, 1983.

[22] I. I. M. Sudarma, I. B. Indramanik, and A. . P. A. Putra, "ANALISA PERBANDINGAN PERENCANAAN STRUKTUR ANTARA PONDASI BORE PILE DENGAN PONDASI TIANG PANCANG (STUDI KASUS PADA PROYEK GEDUNG DPRD BALI)," pp. 15-30, 2015.

[23] A. Setiawan, "Perancangan Struktur Beton Bertulang Berdasarkan SNI 2847 : 2013," pp. $1-2,2016$. 